\title{
Microstructure Characterization of Nanocrystalline Magnesium Ferrite Annealed at Elevated Temperatures by Rietveld Method
}

\author{
Swapan Kumar Pradhan, ${ }^{1}$ Sumanta Sain, ${ }^{1}$ and Hema Dutta ${ }^{2}$ \\ ${ }^{1}$ Department of Physics, The University of Burdwan, Golapbag, West Bengal, Burdwan 713104, India \\ ${ }^{2}$ Department of Physics, Vivekananda College, West Bengal, Burdwan 713103, India \\ Correspondence should be addressed to Swapan Kumar Pradhan, skp_bu@yahoo.com
}

Received 17 August 2011; Accepted 20 September 2011

Academic Editors: H. I. Hsiang, W.-C. Oh, S. Shannigrahi, and S. Wongkasemjit

Copyright ( 2011 Swapan Kumar Pradhan et al. This is an open access article distributed under the Creative Commons Attribution License, which permits unrestricted use, distribution, and reproduction in any medium, provided the original work is properly cited.

\begin{abstract}
Nanocrystalline magnesium ferrite is synthesized at room temperature by high energy ball milling the $\mathrm{MgO}$ and $\alpha$ - $\mathrm{Fe}_{2} \mathrm{O}_{3}(1: 1 \mathrm{~mol}$ fraction) powders. The Rietveld structure and microstructure refinements of X-ray powder diffraction data of $9 \mathrm{~h}$ milled sample reveal the presence of mixed and nearly inverse spinel nanocrystalline Mg-ferrite phases. Postannealing of nanocrystalline powder within 873-1473 K reveals continuous change in cation distribution among the tetrahedral and octahedral sites of mixed spinel lattice leading to nearly inverse spinel structure with increasing temperature. Mixed spinel structure finally transformed into inverse spinel structure after $1 \mathrm{~h}$ of annealing at $1073 \mathrm{~K}$. The ferrite phase becomes completely stoichiometric by solid-state diffusion of unreacted $(\sim 0.3 \mathrm{~mol}$ fraction $) \alpha-\mathrm{Fe}_{2} \mathrm{O}_{3}$ into spinel lattice after $1 \mathrm{~h}$ of annealing at $1273 \mathrm{~K}$. Interestingly, particle sizes of ferrite phases do not increase considerably up to $1073 \mathrm{~K}$ and increase suddenly after transformation of mixed spinel into nearly inverse spinel structure.
\end{abstract}

\section{Introduction}

The synthesis of nanocrystalline spinel ferrites has been investigated intensively in recent years due to their potential applications in nonresonant devices, radio frequency circuits, high-quality filters, rod antennas, transformer cores, $\mathrm{read} /$ write heads for high-speed digital tapes, and operating devices [1-3]. Nowadays, these materials are largely synthesized in nanometric scale for new and improved properties [4-6]. Magnesium ferrite, $\mathrm{MgFe}_{2} \mathrm{O}_{4}$ (Figure 1), is a soft magnetic $n$-type semiconductor material [7], which finds a number of applications in heterogeneous catalysis, adsorption, sensors, and in magnetic technologies. Among the other methods of preparation of nanocrystalline ferrite powders, high-energy ball milling is a very suitable solid-state processing technique for the preparation of nanocrystalline ferrite powders exhibiting new and unusual properties [8-11].

Ferrites have the general formula $\left(\mathrm{M}_{1-x} \mathrm{Fe}_{x}\right)\left[\mathrm{M}_{x} \mathrm{Fe}_{2-x}\right] \mathrm{O}_{4}$. The divalent metal element $\mathrm{M}(\mathrm{Mg}, \mathrm{Zn}, \mathrm{Mn}, \mathrm{Fe}, \mathrm{Co}, \mathrm{Ni}$, or mixture of them) can occupy either tetrahedral eight (A) or sixteen octahedral [B] sites of a cubic mineral spinel $\left(\mathrm{MgAl}_{2} \mathrm{O}_{4}\right)$ structure as depicted by the parentheses or brack- ets, respectively. The structural formula of Mg-ferrite is usually written as $\left(\mathrm{Mg}_{1-x} \mathrm{Fe}_{x}\right)\left[\mathrm{Mg}_{x} \mathrm{Fe}_{2-x}\right] \mathrm{O}_{4}$, where $x$ represents the degree of inversion (defined as the fraction of (A) sites occupied by $\mathrm{Fe}^{3+}$ cations). Depending on distribution of cations in (A) and [B] sites, ferrites may exist in two extreme states-normal $(x=0)$ and inverse $(x=1)$ or in an intermediate mixed state. The magnetic properties of spinel ferrites are strongly dependent on the distribution of the different cations among $(\mathrm{A})$ and $[\mathrm{B}]$ sites. The cation distribution of slowly cooled Mg-ferrite (from $1773 \mathrm{~K}$ to room temperature) was reported $[12,13]$ as nearly inverse spinel lattice with $x=0.9$, but it is also experimentally verified that distribution of cations among these sites depends on material preparation. The complexity of the above formula and the nature of preparation techniques strongly suggest a variation in unit cell composition and possibly a variation in the arrangement of $\mathrm{Mg}^{2+}$ and $\mathrm{Fe}^{3+}$ ions over the available tetrahedral and octahedral sites. These types of disorder should influence the integrated intensity and peak broadening of diffraction lines. In view of the large scattering power of $\mathrm{Fe}^{3+}$ relative to the other ions in the structure, integrated intensities of the diffraction lines of the crystalline 


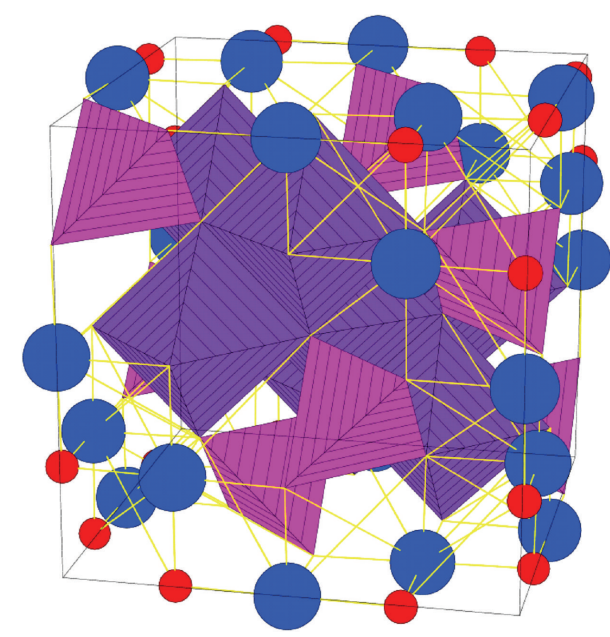

Figure 1: Fragments from the bulk Mg-ferrite normal spinel: Mg$\mathrm{O}$ tetrahedra, Fe-O octahedral; positions of Fe (blue) and oxygen (red) atoms are shown.

Mg-ferrite (cubic, $a=0.83998 \mathrm{~nm}$, space group: $\mathrm{Fd} \overline{3} \mathrm{~m}$, $Z=8$; ICDD PDF \#88-1943) change to a large extent due to occupancy of cations in (A) and [B] sites. As the ionic radii of the cations are quite different, random occupancy of cations in any site will also lead to produce lattice strain due to mismatch in ionic size, which in turn influences the coherently diffracting domain (particle size). To account for all these effects on X-ray powder diffraction patterns of ball-milled and postannealed Mg-ferrites samples, a diffraction profile analysis based on both structure and microstructure simulation is essential.

An important aspect, which was studied only to a limited extent until now $[4,14]$ is related to the thermal stability of mechanically induced structural defects in these solids and the mechanism of their relaxation on heating at elevated temperatures. Since in the process of relaxation of mechanically induced metastable states the advantageous properties of mechanically treated solids are mostly lost, it is necessary to know the lifetime of the activated surface and the time dependence of the relaxation. This understanding would be of principal importance from the scientific point of view in the development of an atomistic and microscopic theory of the mechanochemical processes, as well as from the practical point of view in the application of mechanically treated solids at elevated temperatures.

Nanocrystalline $\mathrm{Mg}$-ferrite powders were produced by ball milling the stoichiometric mixture (1:1 mol\%) of $\mathrm{MgO}$ and $\alpha-\mathrm{Fe}_{2} \mathrm{O}_{3}$. It was found that the prepared ferrite powders are nonstoichiometric one $\left(\sim 3 \mathrm{wt} \% \alpha-\mathrm{Fe}_{2} \mathrm{O}_{3}\right.$ remains unreacted), and the distribution of cations among the tetrahedral and octahedral sites is somewhat different (mixture of mixed and nearly inverse spinels) from the reported value (only nearly inverse spinel) [15]. In the present study, we have examined the $9 \mathrm{~h}$ ball-milled sample for phase transformation kinetics, thermal stability of nanocrystalline ferrite phase, and cation redistribution among (A) and [B] sites at elevated temperatures.

The Rietveld analysis based on structure and microstructure refinement [16-18] has been adopted in the present study for precise determination of several microstructural parameters (change in lattice parameters, particle size, and lattice strain), cation redistribution in terms of occupancy factors of cations at different sites as well as relative phase abundances of this multiphase nanocrystalline material containing a large number of overlapping reflections. However, the selected area electron diffraction pattern (SAED) of $9 \mathrm{~h}$ milled sample could not detect the presence of any secondary phase, and the pattern seems to be composed of single Mgferrite phase.

\section{Experimental}

Accurately weighed powders of $20.15 \mathrm{wt} \% \mathrm{MgO}(\mathrm{M} / \mathrm{s}$ Merck, 99\% purity) and 79.85 wt. $\%$ of $\alpha-\mathrm{Fe}_{2} \mathrm{O}_{3}$ (M/s Glaxo, $99 \%$ purity) were hand-ground in an agate mortar under doubly distilled acetone for more than $5 \mathrm{~h}$ for a homogeneous mixture of the powders. High-energy ball milling of a part of the dried homogeneous powder mixture was conducted in a planetary ball mill (Model P5, M/s Fritsch, $\mathrm{GmbH}$, Germany). The rotation speed of the disk was $325 \mathrm{rpm}$ and that of the vials was $\sim 475 \mathrm{rpm}$. Milling of powder samples was done at room temperature in hardened chrome steel (Fe-1 wt.\% Cr) vial (volume $80 \mathrm{~mL}$ ) using 30 hardened chrome steel balls of $10 \mathrm{~mm}$ diameter at BPMR = $40: 1$. The time of milling varies from $1 \mathrm{~h}$ to $11 \mathrm{~h}$ depending upon the rate of formation of $\mathrm{Mg}$-ferrite phase. The $9 \mathrm{~h}$ ballmilled powder was postannealed at 873, 973, 1073, 1273, and $1473 \mathrm{~K}$ successively each for $1 \mathrm{~h}$ duration in air in a programmable furnace with $5 \mathrm{~K} / \mathrm{min}$ and $20 \mathrm{~K} / \mathrm{min}$ heating and cooling rates, respectively.

The X-ray powder diffraction profiles of unmilled homogeneous powder mixture, ball-milled and postannealed samples were recorded using Ni-filtered $\mathrm{Cu} \mathrm{K}_{\alpha}$ radiation from Philips X'Pert powder diffractometer operated at $40 \mathrm{KV}$ and $40 \mathrm{~mA}$. The background noise and fluorescent radiation were reduced significantly employing a diffracted beam graphite monochromator. For this experiment, $0.5^{\circ}$ divergence slit and $0.5^{\circ}$ receiving slit were used. The step-scan data (of step size $2 \theta=0.02^{\circ}$ and counting time $10 \mathrm{~s}$, in some cases $60 \mathrm{~s}$ ) for the entire angular range $\left(2 \theta=15-100^{\circ}\right)$ were recorded, and crystalline phases were identified by search-match software.

Microstructure characterization of $9 \mathrm{~h}$ ball-milled $\mathrm{Mg}$ ferrite powder has also been made using high-resolution transmission electron microscopes (Model HR-TEM 2100F, JEOL). For TEM study, a pinch of sample was dispersed in ethyl alcohol medium and placed under ultrasonic bath for breaking agglomeration of nanoparticles under vibration. A small drop of alcohol with dispersed/suspended sample particle was placed on the carbon-coated $3 \mathrm{~mm} \mathrm{Cu}$-grid, and the grid was kept overnight under vacuum to get completely dry and well distributed fine particles over the entire area of the carbon-coated grid. HR-TEM was operated at $200 \mathrm{kV}$.

\section{Method of Analysis}

In the present study, we have adopted the Rietveld's powder structure refinement analysis [16-22] of X-ray powder diffraction data to obtain the refined structural parameters, 
such as atomic coordinates, occupancies, lattice parameters, and thermal parameters, and microstructural parameters, such as particle size and r.m.s. lattice strain. For instrumental broadening correction, a specially processed $\mathrm{Si}$ standard [23] was used. The Rietveld's software MAUDWEB 2.24 (Java web start version) [18] is specially designed to refine simultaneously both the structural and microstructure parameters through a least-squares method. The peak shape was assumed to be a pseudo-Voigt $(\mathrm{pV})$ function with asymmetry. The background of each pattern was fitted by a polynomial function of degree 4 . To simulate the theoretical $\mathrm{X}$-ray powder diffraction pattern containing all the $\mathrm{MgO}$, $\alpha-\mathrm{Fe}_{2} \mathrm{O}_{3}$, and $\mathrm{Mg}$-ferrite (normal spinel) and Mg-ferrite (inverse spinel) phases in a single pattern, the following considerations were made:

(i) for $\mathrm{MgO}$ (cubic, space group: $\mathrm{Fm} \overline{3} \mathrm{~m}$ (225), a = $0.42 \mathrm{~nm}$ (ICDD PDF no. 87-0653)), $\mathrm{Mg}^{2+}$, and $\mathrm{O}^{2-}$ in special Wyckoff positions $4 \mathrm{a}$ and $4 \mathrm{~b}$, respectively,

(ii) for $\alpha-\mathrm{Fe}_{2} \mathrm{O}_{3}$ (rhombohedral, space group: $\mathrm{R} \overline{3} \mathrm{c}$ (167), $\mathrm{a}=0.5032$ and $\mathrm{c}=1.3733 \mathrm{~nm}$ (ICDD PDF no. 890599)) with $\mathrm{Fe}$ and $\mathrm{O}$ atoms in special Wyckoff positions $12 \mathrm{c}$ and $18 \mathrm{e}$, respectively,

(iii) for Mg-ferrite (cubic, normal spinel, space group: $\mathrm{Fd} \overline{3} \mathrm{~m}$ (227), $\mathrm{a}=0.83998 \mathrm{~nm}$ (ICDD PDF no. 881943)) with $\mathrm{Mg}^{2+}$ (A-site), $\mathrm{Fe}^{3+}$ [B-site], and $\mathrm{O}^{2-}$ in the $8 \mathrm{a}, 16 \mathrm{~d}$, and 32e Wyckoff positions, respectively,

(iv) for $\mathrm{Mg}$-ferrite (cubic, inverse spinel, space group: $\mathrm{Fd} \overline{3} \mathrm{~m}$ (227), $\mathrm{a}=0.83998 \mathrm{~nm}$ (ICDD PDF no. 881943)) with $0.1 \mathrm{Mg}^{2+}+0.9 \mathrm{Fe}^{3+}$ (A-site), $0.5 \mathrm{Mg}^{2+}$ $+0.5 \mathrm{Fe}^{3+}\left[\mathrm{B}\right.$-site], and $\mathrm{O}^{2-}$ in the $8 \mathrm{a}, 16 \mathrm{~d}$, and $32 \mathrm{e}$ Wyckoff positions, respectively.

3.1. Crystalline Structure Characterization by X-Ray Powder Diffraction. For microstructure characterization, the experimental profiles are fitted with the most suitable $\mathrm{pV}$ analytical function because it takes individual care for both the particle size and strain broadening of the experimental profiles. A detailed mathematical description of the Rietveld analyses has been reported elsewhere [16-22]. Refinement continues till convergence is reached with the value of the quality factor, GoF very close to 1 (varies between 1.1 and 1.3), which confirms the goodness of refinement. The Rietveld's method was successfully applied for determination of the quantitative phase abundances in multiphase materials [1922]. The structure refinement along with size-strain broadening analysis is carried out simultaneously by adopting the standard procedure $[17,18]$.

3.2. Size-Strain Analysis. The basic consideration of this method is the modeling of the diffraction profiles by an analytical function, which is a combination of Cauchy, Gaussian, and asymmetry functions as well. It is well established that the observed peak broadenings of the sample profiles are mainly due to the presence of small particle size and r.m.s. strain inside the particles. The particle size and strain broadening can be approximated better with Cauchy and Gaussian type functions, respectively [19-23]. Being a linear combination of a Cauchy and Gaussian functions, the $\mathrm{pV}$ function is the most reliable peak-shape function and is being widely used in the Rietveld's structure refinement software. The process of successive profile refinements modulated different structural and microstructural parameters of the simulated pattern to fit the experimental diffraction pattern. Profile refinement continues until convergence is reached in each case, with the value of the quality factor (GoF) approaches very close to 1 .

\section{Results and Discussion}

Figure 2(a) represents the X-ray powder diffraction patterns of $9 \mathrm{~h}$ ball-milled and postannealed powders heat treated at different elevated temperatures each for $1 \mathrm{~h}$ duration. It is evident from the plots that the powder pattern of $9 \mathrm{~h}$ ballmilled sample contains only reflections of $\mathrm{Mg}$-ferrite and $\alpha$ $\mathrm{Fe}_{2} \mathrm{O}_{3}$ phases. Reflections of $\alpha-\mathrm{Fe}_{2} \mathrm{O}_{3}$ phase are very weak when compared to those of Mg-ferrite phase. Reflections of $\mathrm{Mg}$-ferrite phase are significantly broad and asymmetric in nature as expected from nanocrystalline material containing significant amount of lattice imperfections. Due to the broad nature of the peaks, some of the reflections of Mg-ferrite phase are either partially or completely overlapped with some reflections of the $\alpha-\mathrm{Fe}_{2} \mathrm{O}_{3}$ phase. In the selected area electron diffraction (SAED) pattern (Figure 2(b)), reflections of these two phases are not well resolved, and it seems that the $9 \mathrm{~h}$ ball-milled sample is composed of only the Mgferrite reflections. It is also evident in the SAED that these reflections are quite broad like a nanocrystalline powder. Since the content of $\alpha-\mathrm{Fe}_{2} \mathrm{O}_{3}$ phase is insignificant in the milled powder, some of the isolated $\alpha-\mathrm{Fe}_{2} \mathrm{O}_{3}$ reflections (Figure 2(a)) did not appear in the SAED pattern. It is therefore impossible to detect the presence of trace amount of $\alpha-\mathrm{Fe}_{2} \mathrm{O}_{3}$ phase even from the transmission electron microscopy image. The Rietveld's powder structure refinement method [16-22] is being utilized for microstructure evolution in several cases of nanocrystalline ball-milled and annealed samples having very broad, asymmetric, partially or even completely overlapping reflections. In the present case, as some of the reflections of $\mathrm{Mg}$-ferrite phase are overlapped with very broadened $\alpha-\mathrm{Fe}_{2} \mathrm{O}_{3}$ reflections, both particle size and lattice strain of individual phases cannot be estimated accurately considering all reflections of respective phases without employing any Rietveld's software based on both structure and microstructure refinements. To show the accuracy in fitting, fitting residuals $\left(\mathrm{I}_{o}-\mathrm{I}_{c}\right)$ are also plotted at the bottom of respective patterns. From the plots of residue, it is evident that except at the peak positions, the residual plots are almost linear and indicate that all the reflections of all three phases are fitted reasonably well. Results revealed from microstructure analysis are shown in Figures 3-6.

A critical comparison between the $9 \mathrm{~h}$ ball-milled nanocrystalline ferrite and ICDD-reported (say, bulk) Mg-ferrite phase reveals that there are anomalies in intensity distribution of some nanocrystalline ferrite peaks. Considering the fact that bulk Mg-ferrite is a nearly inverse spinel, this anomaly in intensity distribution may arise for the following facts: (i) cation distribution among the (A) and [B] 


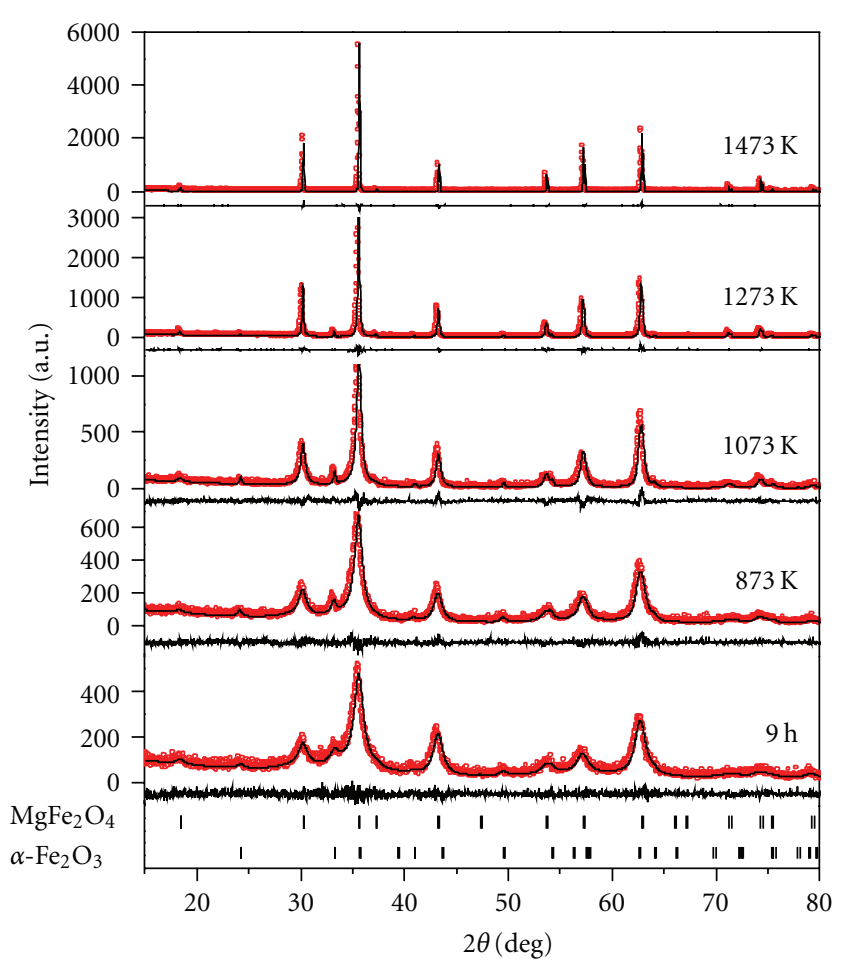

(a)

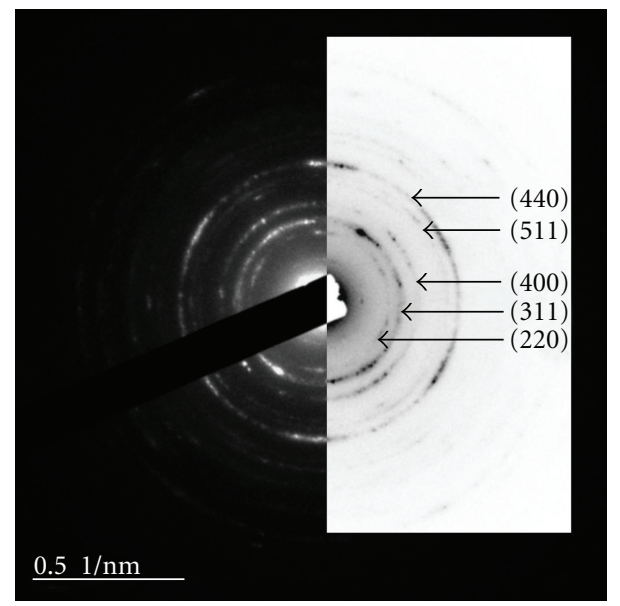

(b)

Figure 2: (a) X-ray powder diffraction patterns of $9 \mathrm{~h}$ ball-milled $\mathrm{MgO}-\alpha-\mathrm{Fe}_{2} \mathrm{O}_{3}$ mixture annealed at different temperatures for $1 \mathrm{~h}$ duration. The peak positions of different phases are shown as small solid bar markers at the bottom of the figure. (b) Indexed selected area electron diffraction pattern of $\mathrm{Mg}$-ferrite powder after annealing the $9 \mathrm{~h}$ milled sample at $1473 \mathrm{~K}$ for $1 \mathrm{~h}$ duration.

sites is somewhat different from the bulk Mg-ferrite and/or (ii) the nanocrystalline ferrite may be an inhomogeneous mixture of both the normal and inverse ferrite phases. The difference in intensity distribution has almost been resolved by considering an additional ferrite phase with a relatively larger lattice parameter and different cation distribution. It has been found from the refinement result of the ballmilled sample that the major nanocrystalline ferrite phase is a mixed spinel, while the minor nanocrystalline phase is nearly an inverse spinel [15] with larger lattice parameter. In the present study, progressive evaluation in the microstructure of the annealed sample has been reported considering both the mixed and inverse spinel phases in the refinement process with equal probabilities of occupancy of both the $\mathrm{Mg}^{2+}$ and $\mathrm{Fe}^{3+}$ cations to be in both the $(\mathrm{A})$ and [B] sites. The occupancy factors of both the cations have been refined during the refinement to fit the intensity distributions of reflections.

As such there is no significant change in the XRD patterns (Figure 2) of ball-milled and the annealed sample at $873 \mathrm{~K}$, but a close observation reveals a change in the intensity ratio of the overlapping reflections of the two phases which indicates the slow change in relative contents of both phases in the annealed samples. However, the content of $\mathrm{Mg}$ ferrite phase increases gradually, but that of $\alpha-\mathrm{Fe}_{2} \mathrm{O}_{3}$ phase decreases slowly with increasing annealing temperature in the temperature range $873-1073 \mathrm{~K}$. A remarkable change in peak broadening, peak asymmetry, peak intensity, and intensity ratio in XRD patterns has been noticed when the postannealed sample was annealed after $1073 \mathrm{~K}$ for $1 \mathrm{~h}$ of duration. Sudden decrease in the content of $\alpha-\mathrm{Fe}_{2} \mathrm{O}_{3}$ phase is noticed from the reduction in the peak intensity values of the reflections of $\alpha-\mathrm{Fe}_{2} \mathrm{O}_{3}$ phase. Peak broadening and peak asymmetry of $\mathrm{Mg}$-ferrite phase decreases significantly with increase in the peak intensity values. Comparing the intensity and line position of individual reflection, it is clearly evident that increase in annealing temperature after $1073 \mathrm{~K}$ results in release in lattice strain and increase in particle size values of Mg-ferrite phase to a large extent. Change in the intensity ratio particularly in the higher angle side may be attributed to the cation redistribution with the solid-state diffusion of $\alpha-\mathrm{Fe}_{2} \mathrm{O}_{3}$ in the lattice of $\mathrm{Mg}$-ferrite. Intensity distribution of $\mathrm{Mg}$-ferrite reflections approaches slowly to the ICDDreported value of the $\mathrm{Mg}$-ferrite with nearly inverse spinel lattice. Further annealing (from $1273 \mathrm{~K}$ to $1473 \mathrm{~K}$ ) results in complete absence of $\alpha-\mathrm{Fe}_{2} \mathrm{O}_{3}$ phase, and samples contain only the $\mathrm{Mg}$-ferrite phase which is nearly an inverse spinel lattice as identified from intensity distribution.

Figure 3 shows the dependence of relative phase abundances of different phases with increasing annealing temperature. The content (volume fraction) of $\alpha-\mathrm{Fe}_{2} \mathrm{O}_{3}$ phase decreases very slowly with annealing temperature and becomes nil at $1473 \mathrm{~K}$. It indicates that the $\alpha-\mathrm{Fe}_{2} \mathrm{O}_{3}$ phase diffuses slowly into the $\mathrm{Mg}$-ferrite lattice. Phase content of mixed Mg-ferrite phase increases, and that of inverse Mgferrite phase decreases initially with increasing annealing temperature in the temperature range $873 \mathrm{~K}-1073 \mathrm{~K}$. This nature of variation depicts the solid-state diffusion of $\alpha$ $\mathrm{Fe}_{2} \mathrm{O}_{3}$ phase into mixed spinel lattice, and the inverse spinel phase has been partially transformed to its mixed counterpart. The mixed spinel phase disappears completely after annealing the ball-milled sample at $1073 \mathrm{~K}$ followed by a rapid increase in the phase content of inverse spinel phase. It signifies that structure of the mixed spinel phase changes suddenly after $1073 \mathrm{~K}$ of annealing temperature. It is interesting to note that after annealing the sample at $1073 \mathrm{~K}$ for $1 \mathrm{~h}$ duration, rate of diffusion of $\alpha-\mathrm{Fe}_{2} \mathrm{O}_{3}$ in $\mathrm{Mg}$-ferrite lattice 


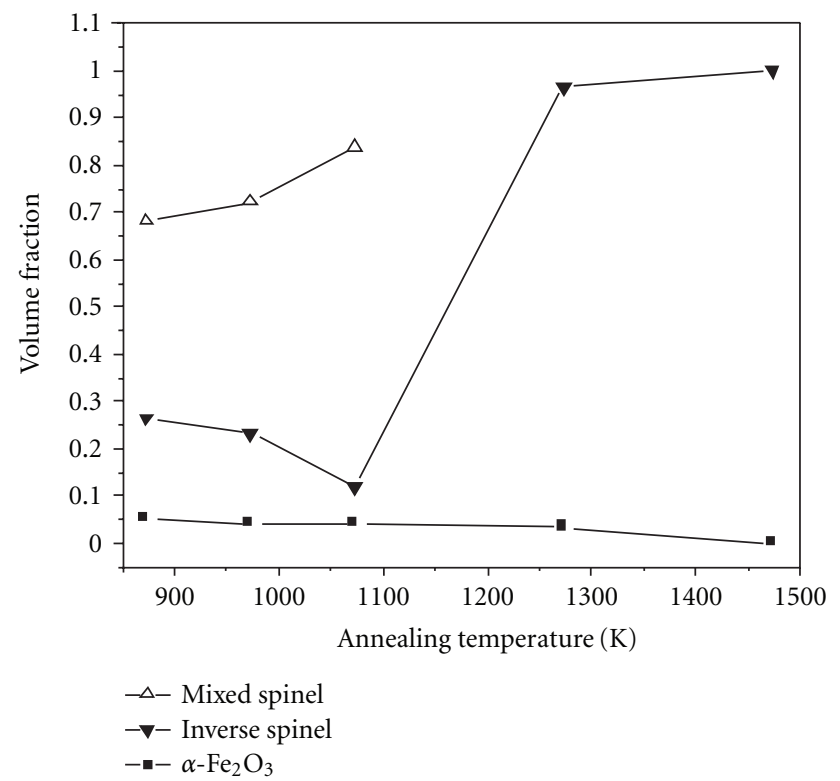

FIGURE 3: Nature of variations of volume fractions of different phases obtained by annealing $9 \mathrm{~h}$ ball-milled $\mathrm{MgO}-\alpha-\mathrm{Fe}_{2} \mathrm{O}_{3}$ mixture powders with increasing temperature.

increases and that may result in decrease in $\mathrm{Fe}^{3+}$ cation deficiency nonstoichiometric Mg-ferrite phase matrix. Redistribution of cations inside mixed spinel leads to the complete transformation of mixed spinel to inverse spinel in the annealing temperature range $1073 \mathrm{~K}-1273 \mathrm{~K}$ which results the rapid increase in phase content of $\mathrm{Mg}$-ferrite phase with nearly inverse spinel lattice. Further annealing of the sample after $1273 \mathrm{~K}$ for $1 \mathrm{~h}$ duration results complete solidstate diffusion of unreacted $\alpha-\mathrm{Fe}_{2} \mathrm{O}_{3}$ phase into the inverse spinel lattice, and the composition of the $\mathrm{Mg}$-ferrite becomes completely stoichiometric.

In the present work, we found that the nanostructured $\mathrm{MgFe}_{2} \mathrm{O}_{4}$ prepared by high-energy milling is metastable with respect to structural changes at elevated temperatures. Sepelak et al. [24] also found that the thermal stability of the mechanosynthesized product extends up to $623 \mathrm{~K}$. Above this temperature, a gradual crystallization of the nanoscale $\mathrm{MgFe}_{2} \mathrm{O}_{4}$ powders takes place. In the present case, we found the thermal stability up to $1073 \mathrm{~K}$. During the annealing process, the nonequilibrium cation distribution relaxes toward their equilibrium configuration.

The cation distribution in $\mathrm{MgFe}_{2} \mathrm{O}_{4}$, upon which many physical and chemical properties depend, is a complex function of processing parameters and depends on the preparation method of the material [14]. The cation distribution in mechanosynthesized spinel ferrites from Mössbauer spectra and/or X-ray diffraction patterns is not as straightforward as is frequently claimed in the literature. Sepelak et al. [24] reported for the first time the microstructure characterization and cation distribution in nanosized $\mathrm{MgFe}_{2} \mathrm{O}_{4}$ synthesized in a one-step mechano-chemical process. They also confirmed that the nonuniform cation distribution within $\mathrm{MgFe}_{2} \mathrm{O}_{4}$ nanoparticles by means of Mössbauer spectroscopy is consistent with the results of Rietveld analysis

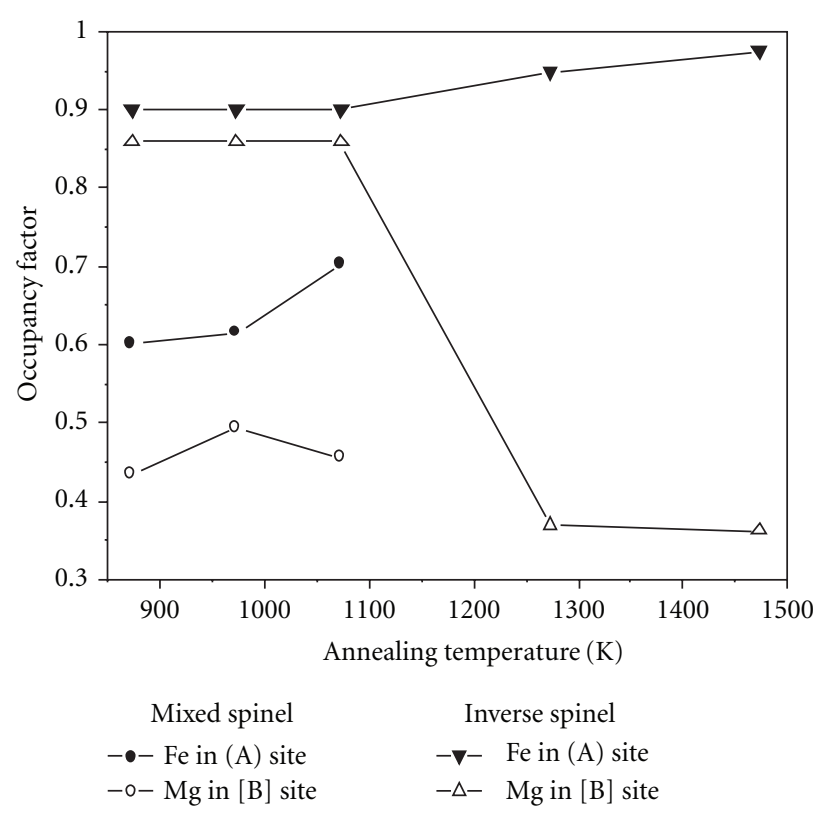

FIGURE 4: Nature of variations of occupancy factors of cations in different sites of $\mathrm{Mg}$-ferrite with increasing temperature.

of the XRD data [15] showing that the mechanosynthesized material consists of two spinel phases with different cation distributions. In another paper, Sepelak et al. reported that the enhanced coercivity in nanosized $\mathrm{MgFe}_{2} \mathrm{O}_{4}$ can be attributed to the high volume of the grain boundaries with a nonequilibrium cation distribution and spin canting [25].

In the present study, mixed spinel phase is a major one instead of inverse spinel in the ball-milled sample due to $\mathrm{Fe}^{3+}$ cation deficiency inside the mixed spinel matrix at room temperature. In the annealing temperature range $873 \mathrm{~K}-$ $1073 \mathrm{~K}$, no change is observed in the occupancy factors of cations (Figure 4) in the inverse spinel phase. However, the occupancy of $\mathrm{Mg}^{2+}$ cation on [B] site increases and then decreases, and $\mathrm{Fe}^{3+}$ cation on (A) site increases with annealing temperature in mixed spinel phase. It is interesting to note that the occupancy of $\mathrm{Mg}^{2+}$ cation on [B] site drops suddenly from $\sim 0.85$ to $\sim 0.35$ and that of $\mathrm{Fe}^{3+}$ cation on (A) site increases inside inverse spinel matrix followed by the transformation of mixed spinel phase to its inverse counterpart at $1073 \mathrm{~K}$. These observations suggest that at higher annealing temperature with increasing solid-state diffusion of $\alpha-\mathrm{Fe}_{2} \mathrm{O}_{3}$, random distribution of cations in the mixed spinel proceeds towards the inverse spinel lattice. In the annealing temperature range $1073 \mathrm{~K}-1273 \mathrm{~K}$, rapid increase in the occupancy of $\mathrm{Fe}^{3+}$ cation on (A) site in the inverse spinel leads to a significant growth of inverse spinel phase in the cost of excess $\alpha-\mathrm{Fe}_{2} \mathrm{O}_{3}$ phase. Further, annealing results in a slight increment in the increase of $\mathrm{Fe}^{3+}$ cation on (A) site and decrease of $\mathrm{Mg}^{2+}$ cation on [B] site in inverse spinel phase in favour of almost stoichiometric composition.

The variations of lattice parameters of different phases with annealing temperature are shown in Figure 5. As the cation compositions of inverse and mixed phases are different, they also have different lattice parameter value at 


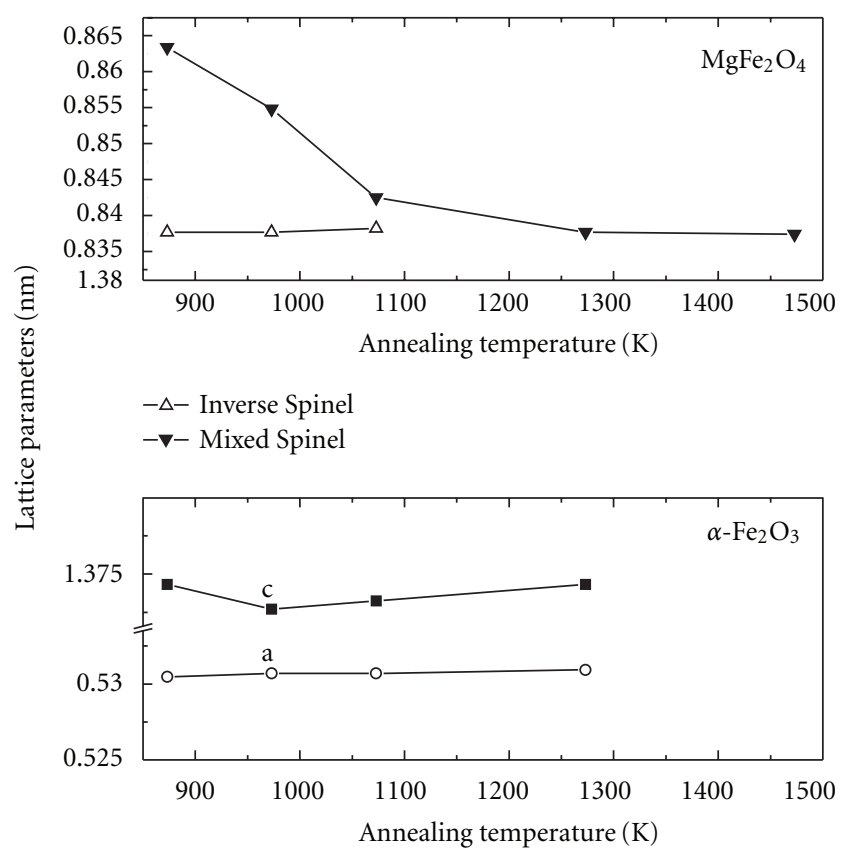

FIGURE 5: Nature of variations of lattice parameters of different phases obtained by annealing $9 \mathrm{~h}$ ball-milled $\mathrm{MgO}-\alpha-\mathrm{Fe}_{2} \mathrm{O}_{3}$ mixture powders with increasing temperature.

room temperature. The cation distribution in mixed spinel proceeds towards the inverse spinel with increasing annealing temperature due to solid-state diffusion of nanocrystalline $\alpha-\mathrm{Fe}_{2} \mathrm{O}_{3}$ into mixed spinel matrix. Lattice parameter of cubic mixed spinel phase does not change significantly with annealing temperature but that of inverse spinel phase decreases initially very rapidly and proceeds towards that of mixed spinel phase. After annealing the sample for $1073 \mathrm{~K}$ for $1 \mathrm{~h}$ duration, lattice parameter values of both the phases become nearly equal. Lattice parameter value of inverse spinel phase then approaches slowly to mixed spinel lattice parameter with increasing annealing temperature. This nature of variation of inverse spinel lattice parameter may be attributed to the transformation of mixed spinel phase having major phase content to the inverse phase. A steady-state nature of lattice parameter variation of inverse spinel phase at higher annealing temperature indicates that the cation distribution among the $(\mathrm{A})$ and $[\mathrm{B}]$ sites becomes saturated at the last stage of annealing. Lattice parameters of rhombohedral $\alpha-\mathrm{Fe}_{2} \mathrm{O}_{3}$ phase do not change significantly with annealing temperature.

It is evident from Figure 2 that the peak broadening decreases and peak intensity increases with increasing annealing temperature. The peak broadening in the ball-milled sample may arise primarily due to small crystallite size and lattice strain. These lattice imperfections can be reduced to a large extent by postannealing the ball-milled powder at elevated temperatures. The noticeable change in XRD patterns with increasing annealing temperature indicates the continuous growth of Mg-ferrite particles due to continuous release in lattice strain followed by rearrangement of ions in respective proper sites. The particle size (coherently diffracting domain) and r.m.s. lattice strain values for individual

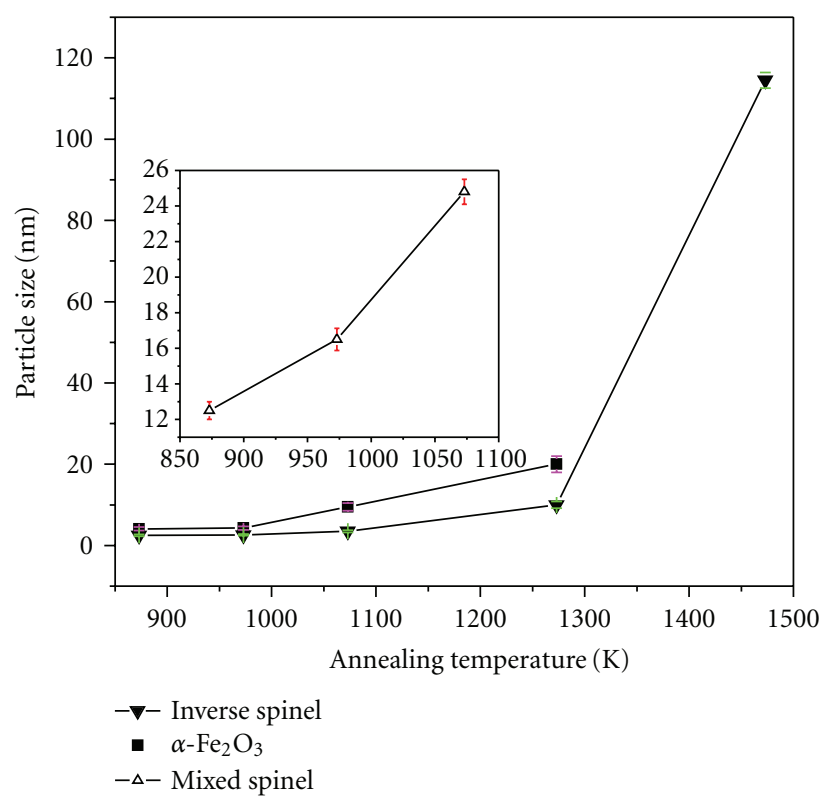

(a)

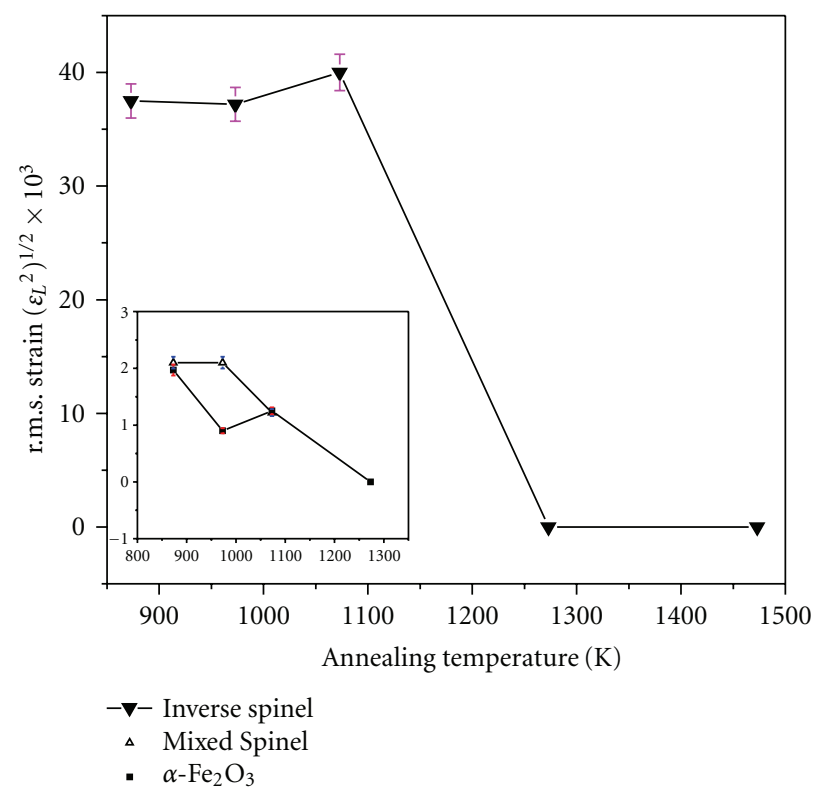

(b)

FigURE 6: Nature of variations of (a) particle sizes, (b) r.m.s strains of different phases obtained by annealing $9 \mathrm{~h}$ ball-milled $\mathrm{MgO}-\alpha-$ $\mathrm{Fe}_{2} \mathrm{O}_{3}$ mixture powders with increasing temperature.

phases in postannealed samples have been estimated from the Rietveld's refinement and plotted in Figures 6(a) and 6(b), respectively. Observation from Figure 6(a) indicates that the particle size of mixed spinel phase increases from $\sim 12 \mathrm{~nm}$ to $\sim 25 \mathrm{~nm}$ within the temperature range $873 \mathrm{~K}-$ $1073 \mathrm{~K}$. There is no considerable change in particle sizes of inverse spinel phase up to $1073 \mathrm{~K}$. A significant increase in the particle size value of inverse spinel phase can be noticed from the nature of the plot after annealing the sample at $1473 \mathrm{~K}$ for $1 \mathrm{~h}$ duration. It is interesting to note that $\alpha-\mathrm{Fe}_{2} \mathrm{O}_{3}$ has been completely diffused into inverse spinel lattice and results in formation of a stoichiometric inverse spinel lattice. 
The significant grain growth may be attributed to the complete ordering of inverse spinel lattice with proper placement of cations at their respective tetrahedral and octahedral positions. Particle size of $\alpha-\mathrm{Fe}_{2} \mathrm{O}_{3}$ phase slowly increases with annealing temperature in a usual manner.

The r.m.s. lattice strain values of both $\alpha-\mathrm{Fe}_{2} \mathrm{O}_{3}$ and mixed spinel phases are in general decreasing in nature with annealing temperature in a usual manner. The inverse spinel phase grows with a large lattice strain. Initially, the inverse spinel lattice could not release strain, rather strain increases slightly with increasing temperature upto $1073 \mathrm{~K}$. It suggests that up to that temperature there was no significant change in cation distribution in the lattice, and the small increment in lattice strain may be attributed to the solid-state diffusion of $\alpha-\mathrm{Fe}_{2} \mathrm{O}_{3}$ into the lattice.

The r.m.s. strain value drops suddenly to almost nil after annealing the sample at $1273 \mathrm{~K}$ for $1 \mathrm{~h}$ duration. It is interesting to note that the mixed spinel is completely absent after that temperature of annealing. It seems that the annealing temperature favours distribution cations to their preferred sites. As a result, lattice strain reduces to nil when samples are annealed at higher range of temperature $1273 \mathrm{~K}-1473 \mathrm{~K}$. It is also evident from the figure that in the same temperature range particle size of inverse phase increases abruptly from $\sim 10 \mathrm{~nm}$ to $\sim 120 \mathrm{~nm}$ which may be considered as particle size growth of inverse spinel phase in a less constraint environment.

\section{Conclusions}

Nanocrystalline Mg-ferrite powders have been prepared by high-energy ball milling of stoichiometric mixture of $\mathrm{MgO}$ and $\alpha-\mathrm{Fe}_{2} \mathrm{O}_{3}$ powders. Analysis of $9 \mathrm{~h}$ ball-milled samples by Rietveld's method reveals the presence of mixed and nearly inverse spinel nanocrystalline $\mathrm{Mg}$-ferrite as major and minor phases, respectively, with a small amount $(\sim 3 \mathrm{wt} \%)$ of unreacted $\alpha-\mathrm{Fe}_{2} \mathrm{O}_{3}$. Nanocrystalline ball-milled powder was postannealed within $873-1473 \mathrm{~K}$ temperature range. Structural changes and microstructure characterization of $\alpha-\mathrm{Fe}_{2} \mathrm{O}_{3}$ and both the mixed and nearly inverse spinel Mgferrite phases in the postannealed samples have been investigated by Rietveld's analysis of X-ray powder diffraction data for the first time, to best of our knowledge. The following important observations may be summarized as follows.

Distribution of cations among (A) and [B] sites in mixed spinel matrix changes continuously, and occupancy of $\mathrm{Fe}^{3+}$ in (A) site (inverse spinel) increases with increasing annealing temperature. Mixed spinel structure changes to inverse spinel after $1 \mathrm{~h}$ annealing at $1073 \mathrm{~K}$. The composition of Mgferrite becomes completely stoichiometric one by solid-state diffusion of unreacted $\alpha-\mathrm{Fe}_{2} \mathrm{O}_{3}$ into nearly inverse spinel lattice after $1 \mathrm{~h}$ of annealing at $1273 \mathrm{~K}$. Particle sizes of inverse spinel do not increase considerably up to $1073 \mathrm{~K}$ and increase suddenly with a large release in r.m.s. lattice strain after transformation of mixed spinel to a nearly inverse spinel structure.

The present study reveals that the nanocrystalline stoichiometric nearly inverse spinel $\mathrm{Mg}$-ferrite can be formed completely by postannealing the $9 \mathrm{~h}$ ball-milled powder sample.

\section{Acknowledgments}

One of the authors, S. K. Pradhan, wishes to thank UGC authority, India for providing grants for instruments under DSA III and COSIST programs. The authors are also thankful to Dr. V. Petkov, Department of Physics, Central Michigan University, USA for providing X-ray diffraction facility.

\section{References}

[1] P. Ravindranathan and K. C. Patil, "Novel solid solution precursor method for the preparation of ultrafine Ni-Zn ferrites," Journal of Materials Science, vol. 22, no. 9, pp. 3261-3264, 1987.

[2] H. Igarashi and K. Okazaki, "Effects of porosity and grain size on the magnetic properties of nizn ferrite," Journal of the American Ceramic Society, vol. 60, no. 1-2, pp. 51-54, 1977.

[3] S. M. Antao, I. Hassan, and J. B. Parise, "Cation ordering in magnesioferrite, $\mathrm{MgFe}_{2} \mathrm{O}_{4}$, to $982^{\circ} \mathrm{C}$ using in situ synchrotron X-ray powder diffraction," American Mineralogist, vol. 90, no. 1, pp. 219-228, 2005.

[4] V. Sepelak, D. Baabe, D. Mienert et al., "Evolution of structure and magnetic properties with annealing temperature in nanoscale high-energy-milled nickel ferrite," Journal of Magnetism and Magnetic Materials, vol. 257, no. 2-3, pp. 377-386, 2003.

[5] M. Pavlovic, C. Jovalekic, A. S. Nikolic, D. Manojlovic, and N. Sojic, "Mechanochemical synthesis of stoichiometric $\mathrm{MgFe}_{2} \mathrm{O}_{4}$ spinel," Journal of Materials Science, vol. 20, no. 8, pp. 782-787, 2009.

[6] P. Holec, J. Plocek, D. Niznansky, and J. P. Vejpravova, "Preparation of $\mathrm{MgFe}_{2} \mathrm{O}_{4}$ nanoparticles by microemulsion method and their characterization," Journal of Sol-Gel Science and Technology, vol. 51, no. 3, pp. 301-305, 2009.

[7] R. J. Willey, P. Noirclerc, and G. Busca, "Preparation and characterization of magnesium chromite and magnesium ferrite aerogels," Chemical Engineering Communications, vol. 123, pp. 1-16, 1993.

[8] P. Druska, U. Steinike, and V. Sepelak, "Surface structure of mechanically activated and of mechanosynthesized zinc ferrite," Journal of Solid State Chemistry, vol. 146, no. 1, pp. 1321, 1999.

[9] V. Sepelak, A. Y. Rogachev, U. Steinike, D. C. Uccker, S. Wibmann, and K. D. Becker, "Structure of nanocrystalline spinelferrite produced by high-energy ball-milling method," Acta Crystallographica A, vol. 52, supplement, p. 367, 1996.

[10] I. P. Muthuselvam and R. N. Bhowmik, "Mechanical alloyed $\mathrm{Ho}^{3+}$ doping in $\mathrm{CoFe}_{2} \mathrm{O}_{4}$ spinel ferrite and understanding of magnetic nanodomains," Journal of Magnetism and Magnetic Materials, vol. 322, no. 7, pp. 767-776, 2010.

[11] M. Sinha, H. Dutta, and S. K. Pradhan, "X-ray characterization and phase transformation kinetics of ball-mill prepared nanocrystalline $\mathrm{Mg}$ - Zn-ferrite at elevated temperatures," Physica E, vol. 33, no. 2, pp. 367-369, 2006.

[12] N. W. Grimes, R. J. Hilleard, J. Waters, and J. Yerkess, "An $\mathrm{X}$-ray diffraction study of disorder in $\mathrm{MgFe}_{2} \mathrm{O}_{4}$ and $\mathrm{Mg}(\mathrm{Cr}$, Al) $\mathrm{O}_{4}$," Journal of Physics C, vol. 1, no. 3, pp. 663-672, 1968.

[13] G. E. Bacon and F. F. Roberts, "Neutron-diffraction studies of magnesium ferrite-aluminate powders," Acta Crystallographica, vol. 6, pp. 57-62, 1953. 
[14] V. Sepelak, D. Schultze, F. Krumeich, U. Steinike, and K. D. Becker, "Mechanically induced cation redistribution in magnesium ferrite and its thermal stability," Solid State Ionics, vol. 141-142, pp. 677-682, 2001.

[15] S. K. Pradhan, S. Bid, M. Gateshki, and V. Petkov, "Microstructure characterization and cation distribution of nanocrystalline magnesium ferrite prepared by ball milling," Materials Chemistry and Physics, vol. 93, no. 1, pp. 224-230, 2005.

[16] H. M. Rietveld, "Line profiles of neutron powder-diffraction peaks for structure refinement," Acta Crystallographica, vol. 22, pp. 151-152, 1967.

[17] H. M. Rietveld, "A profile refinement method for nuclear and magnetic structures," Journal of Applied Crystallography, vol. 2, pp. 65-71, 1969.

[18] L. Lutterotti, "MAUD version 2.24 ," 2010, http://www.ing .unitn.it/maud.

[19] U. K. Bhaskar, S. Bid, and S. K. Pradhan, "Mechanochemical solid state synthesis of $\left(\mathrm{Cd}_{0.8} \mathrm{Zn}_{0.2}\right) \mathrm{S}$ quantum dots: microstructure and optical characterizations," Journal of Alloys and Compounds, vol. 509, no. 10, pp. 4176-4184, 2011.

[20] H. Dutta, M. Sinha, Y. C. Lee, and S. K. Pradhan, "Microstructure characterization and phase transformation kinetics of ball-mill prepared nanocrystalline Mg-Zn-ferrite by Rietveld's analysis and electron microscopy," Materials Chemistry and Physics, vol. 105, no. 1, pp. 31-37, 2007.

[21] M. Sinha, H. Dutta, and S. K. Pradhan, "Phase stability of nanocrystalline $\mathrm{Mg}$-Zn ferrite at elevated temperatures," Japanese Journal of Applied Physics, vol. 47, no. 11, pp. 8667-8672, 2008.

[22] S. Sain, S. Patra, and S. K. Pradhan, "Microstructure and optical band-gap of mechano-synthesized $\mathrm{Cd}_{x} \mathrm{Zn}_{1-} \mathrm{S}$ quantum dots," Journal of Physics D, vol. 44, no. 7, Article ID 075101, 8 pages, 2011.

[23] J.G.M.V. Berkum, Strain fields in crystalline of materials, Ph.D. thesis, Delft University of Technology, Delft, The Netherlands, 1994.

[24] V. Sepelak, A. Feldhoff, P. Heitjans et al., "Nonequilibrium cation distribution, canted spin arrangement, and enhanced magnetization in nanosized $\mathrm{MgFe}_{2} \mathrm{O}_{4}$ prepared by a one-step mechanochemical route," Chemistry of Materials, vol. 18, no. 13, pp. 3057-3067, 2006.

[25] V. Sepelak, D. Baabe, D. Mienert, F. J. Litterst, and K. D. Becker, "Enhanced magnetisation in nanocrystalline high-energy milled $\mathrm{MgFe}_{2} \mathrm{O}_{4}$," Scripta Materialia, vol. 48, no. 7, pp. 961966, 2003. 

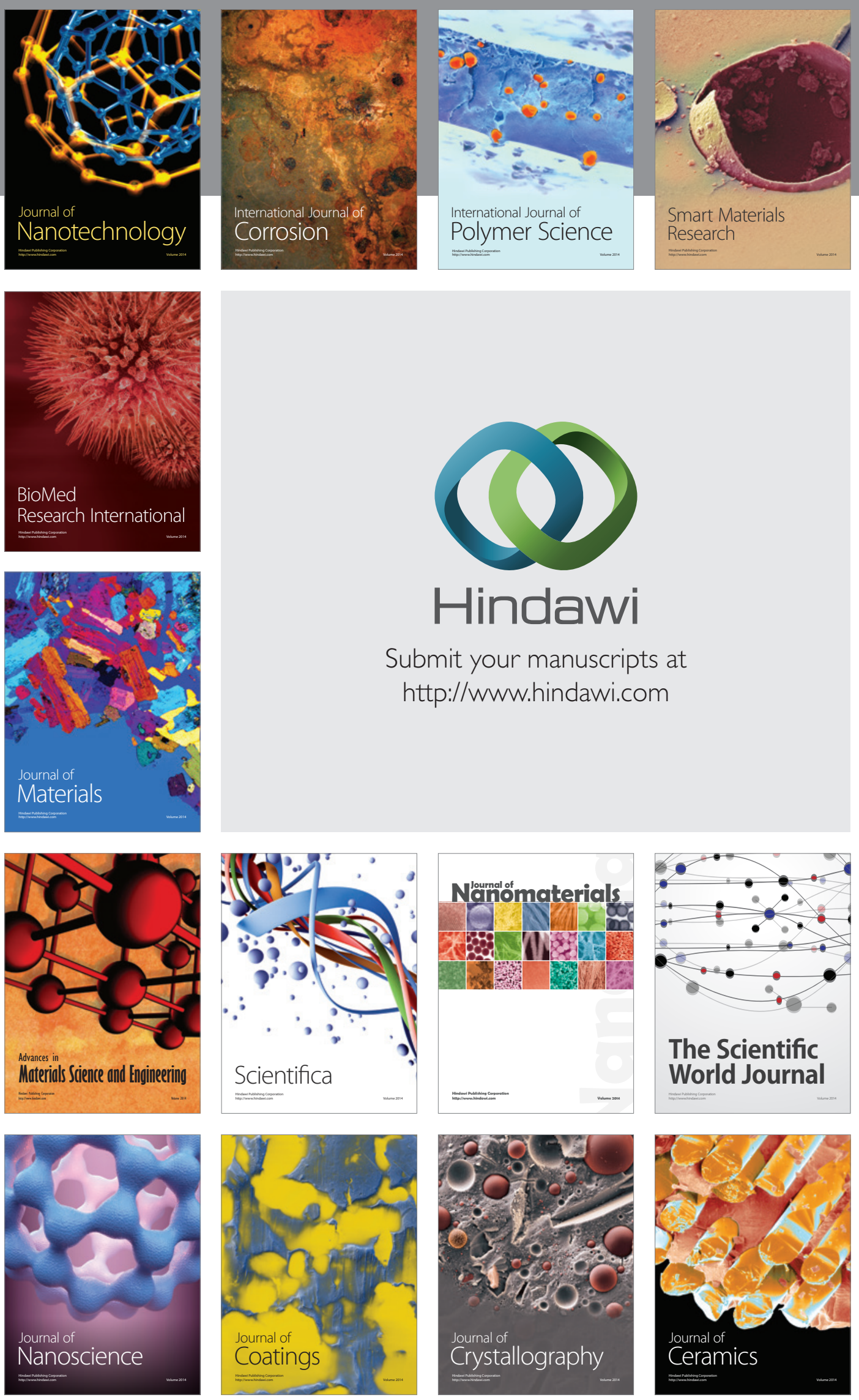

The Scientific World Journal

Submit your manuscripts at

http://www.hindawi.com

\section{World Journal}

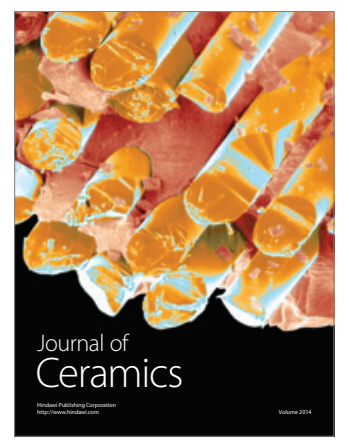

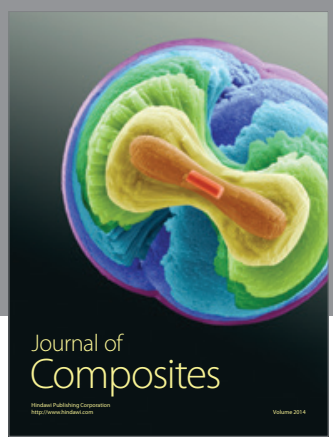
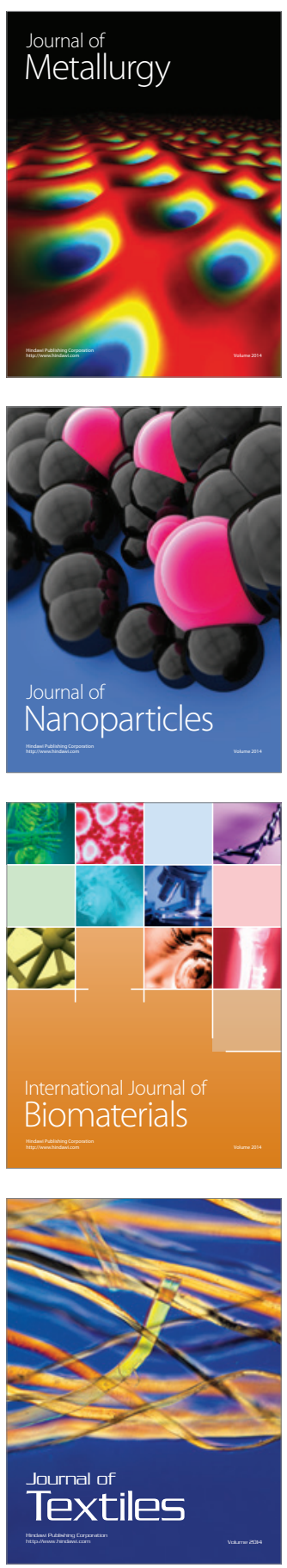